\title{
ABSOLUTELY MONOTONIC FUNCTIONS INVOLVING THE COMPLETE ELLIPTIC INTEGRALS OF THE FIRST KIND WITH APPLICATIONS
}

\author{
ZHEN-HANG YANG AND JING-FENG TIAN*
}

Abstract. Let $\mathscr{K}(r)$ be the complete elliptic integral of the first kind. In this paper, we prove that the function $F_{p}(x)=(1-x)^{p} \exp \mathscr{K}(\sqrt{x})$ is absolutely monotonic on $(0,1)$ if and only if $p \leqslant$ $\pi / 8$, and $-F_{p}^{\prime}(x)$ is absolutely monotonic on $(0,1)$ if and only if $1 / 2 \leqslant p \leqslant(\pi+4+\sqrt{16-\pi}) / 8$. This generalizes a known result and gives several new inequalities involving the complete elliptic integral of the first kind.

Mathematics subject classification (2020): Primary 33E05, 26A48; Secondary 40A05, $29 \mathrm{~B} 62$.

Keywords and phrases: Complete elliptic integrals of the first kind, absolute monotonicity, hypergeometric series, recurrence method, inequality.

\section{REFERENCES}

[1] J. M. Borwein, P. B. Borwein, Pi and the AGM, John Wiley and Sons, 1987, New York.

[2] G. D. Anderson, M. K. Vamanamurthy, M. Vuorinen, Functional inequalities for complete elliptic integrals and their ratios, SIAM J. Math. Anal. 21 (1990), no. 2, 536-549.

[3] G. D. Anderson, M. K. Vamanamurthy, M. Vuorinen, Functional inequalities for hypergeometric functions and complete elliptic integrals, SIAM J. Math. Anal. 23 (1992), no. 2, 512-524.

[4] G. D. Anderson, R. W. Barnard, K. C. Richards, M. K. Vamanamurthy, M. Vuorinen, Inequalities for zero-balanced hypergeometric functions, Trans. Amer. Math. Soc. 347 (1995), no. 5, 1713-1723.

[5] S.-L. Qiu, M. K. VAmAnAmURthy, Sharp estimates for complete elliptic integrals, SIAM J. Math. Anal. 27 (1996), 823-834.

[6] S.-L. Qiu, M. K. Vamanamurthy, M. Vuorinen, Some inequalities for the growth of elliptic integrals, SIAM J. Math. Anal. 29 (1998), 1224-1237.

[7] S. L. QIU, M. VuORINEN, Duplication inequalities for the ratios of hypergeometric functions, Forum Math. 12 (2000), 109-133.

[8] H. Alzer, S.-L. QIU, Monotonicity theorems and inequalities for the complete elliptic integrals, J. Comput, Appl. Math. 172 (2004), 289-312.

[9] H. AlzER, K. Richards, Inequalities for the ratio of complete elliptic integrals, Proc. Amer. Math. Soc. 145 (2017), no. 4, 1661-1670.

[10] Z.-H. YANG, W.-M. QIAN, YU-M., CHU, Monotonicity properties and bounds involving the complete elliptic integrals of the first kind, Math. Inequal. Appl. 21 (2018), no. 4, 1185-1199.

[11] K. C. RICHARDS, A note on inequalities for the ratio of zero-balanced hypergeometric functions, Proc. Amer. Math. Soc. Ser. B 6 (2019), 15-20.

[12] Z.-H. YANG, J. TIAN, Sharp inequalities for the generalized elliptic integrals of the first kind, Ramanujan J. 48 (2019), 91-116.

[13] Z.-H. YANG, J.-F. TIAN, Convexity and monotonicity for elliptic integrals of the first kind and applications, Appl. Anal. Discrete Math. 13 (2019), 240-260.

[14] M.-K. WANG, W. ZhANG, Y.-M. Chu, Monotonicity, convexity and inequalities involving the generalized elliptic integrals, Acta Math. Sci. 39B (2019), no. 5, 1440-1450.

[15] Z.-H. YANG, Y.-M. CHU, W. ZHANG, High accuracy asymptotic bounds for the complete elliptic integral of the second kind, Appl. Math. Comput. 348 (2019), 552-564. 
[16] Z.-H. YANG, J.-F. TIAN, Y.-R. ZHU, A rational approximation for the complete elliptic integral of the first kind, Math. 8 (2020), 635.

[17] Z.-H. YANG, W.-M. QIAN, W. ZHANG, Y.-M. CHU, Notes on the complete elliptic integral of the first kind, Math. Inequal. Appl. 23 (2020), no. 1, 77-93.

[18] M.-K. Wang, H.-H. ChU, Y.-M. Li, Y.-M. CHU, Positive answers to three conjectures on the convexity of the complete elliptic integral proposed by Yang and Tian, Appl. Anal. Discrete Math. 14 (2020), 255-271.

[19] D. V. WidDER, The Laplace Transform, Princeton University Press, Princeton, 1941/1946.

[20] C.-P. Chen, F. QI, The best bounds in Wallis' inequality, Proc. Amer. Math. Soc. 133 (2004), no. 2, $397-401$.

[21] R. A. Rosenbaum, Subadditive functions, Duke Math. J. 17 (1950), 227-242.

[22] M. Petrović, Sur une équation fonctionnelle, Publ. Math. Univ. Belgrade 1 (1932), 149-156. 